\title{
Ocean Literacy There's More to it Than Content
}

\author{
BY CYNTHIA CUDABACK
}

Why do you study the ocean? Most oceanographers with whom I've discussed this question are fascinated by the ocean as a scientific subject, and also want to contribute to its wellbeing. Many promote ocean stewardship through their research. However, when teaching introductory courses, these same people often find that covering ocean science leaves them with little or no time to discuss ocean stewardship.

I would like to suggest a new approach to teaching college-level introductory oceanography. Most students in these courses will not have careers in science, but they are all newly minted voters. Many students express a personal and passionate concern for the ocean (Cudaback, 2006), and are eager to learn what they can do to help the ocean. We, as educators, can provide them with the tools they need.

\section{DEFINING OCEAN LITERACY}

There are several published definitions of ocean literacy, mostly concerned with scientific content (e.g., Centers for Ocean Sciences Education Excellence [COSEE], 2006; Garrison, 2007). By contrast, public surveys focus on attitudes about ocean stewardship (Belden Russonelo \& Stewart and American Viewpoint, 1999; American Association for the Advancement of Science, 2004). I believe the most important definition is that an ocean-literate person understands ocean science, can communicate about the ocean, and is able to make informed decisions that affect the ocean (COSEE, 2006).

Most of our teaching addresses the first two parts of the definitionunderstanding and communication. We answer the big question, "How does the ocean work?" Answers to this question may be organized using the seven essential principles of ocean literacy (COSEE, 2006) or Tom Garrison's “top ten” (Garrison, 2007), and details are found in several textbooks.

For students to make informed decisions that affect the ocean, they need more from us than scientific knowledge. They need to know how their actions affect the ocean, and they need positive attitudes about science and stewardship. That is, they must perceive science as a tool they can use to protect the ocean. I find it convenient to organize these learning objectives using the following 2 x 2 matrix:

\begin{tabular}{|c|c|}
\hline Science & Stewardship \\
Content & Content \\
\hline Science & Stewardship \\
Attitudes & Attitudes \\
\hline
\end{tabular}

Most oceanography courses cover the Science Content quadrant, so I shall limit my discussion to the other three quadrants.

The Stewardship Content quadrant contains answers to the big question, "How do my actions affect the ocean?" For the most part, complete answers to this question are not found in textbooks. Most college-level introductory texts have a single chapter about human impacts, and that chapter may or may not be up to date. Conservation organizations are a good source for this type of information, but as instructors, we need to put together a solid list of key points. I offer a preliminary list of facts, just to get the conversation started:

- The vast majority of ocean pollution is runoff from land.

- At the current rate of global warming, we may experience a meter of sea level rise in this century.

- Coastal development destroys vital nursery habitats and increases coastal erosion.

- The oceans are being depleted of fish.

- Individuals' actions can make a difference to the ocean.

Knowing the facts is a good start, but for students to put their learning into action, they need positive attitudes about ocean 
stewardship. For students to make decisions that benefit the ocean, they should feel (1) concerned about, (2) responsible for, and (3) empowered to improve the wellbeing of the ocean.

Finally, for students to use science as an effective tool for environmental decision-making, they must have positive attitudes about science. They need to believe that science is (1) a process, not a set of facts, (2) a tool that they can use, and (3) a way to understand the real world.

\section{TEACHING OCEAN LITERACY}

Topics related to ocean stewardship need not be tacked onto an already busy schedule. Instead, human impacts can help frame our teaching of ocean science. The hydrologic cycle moves pollutants as well as water. The structure of the water molecule and the density of ice determine the effect of melting the Arctic and Antarctic ice caps. The high heat capacity of water explains the ocean's vital importance in climate change. The dangers of overfishing could frame the discussion of marine ecosystems. But most of all, students need to know what to do with this information. They need to learn specific actions that can make a difference to the ocean.

The best sources of information on simple steps that make a difference are the Web sites of marine conservation organizations. I encourage students to visit these Web sites and decide which simple actions fit best into their own lives. This exercise is easily adaptable to any classroom. Everyday actions, such as driving less and recycling more, make a difference no matter where you live, and they relate to large-scale problems such as global warming.
By contrast, regional issues, such as upgrading sewage treatment plants and planning coastal development, are addressed through the political process. I developed some in-depth case studies for particular regions and made them available on my Web site (see http:// cynthiacudaback.org/Bootkext/bootkext. htm). This process is time consuming, but students respond very positively to learning about issues in their own backyard.

Teaching about human impacts on the ocean has a positive impact on student attitudes about ocean stewardship. For example, at the end of my course, students showed a significant increase in their understanding that Earth's resources are limited. Here we walk a fine line. It is not our role as educators to promote a political agenda, and we cannot grade students on their levels of concern for the wellbeing of the ocean.

However, we can model that concern and teach the skills that empower students to act if they choose to do so.

A well-taught course should improve student attitudes about the nature and relevance of science. Discussing the scientific process and its impact on environmental decision-making can improve these attitudes. Active learning is, of course, vital to understanding the process of science; I personally favor extensive in-class discussion and daily writing assignments. Teaching about the scientific issues involved in decisions that affect the ocean can underscore the realworld value of scientific understanding.

If you choose to teach the science of ocean stewardship, you may want to test your students' understanding and attitudes. My ocean literacy Web site offers an extensive bibliography and a survey for measuring all four aspects of ocean literacy (see http://cynthiacudaback.org/ Education/ocean_literacy.html). Or, you can simply ask the students what they learned-here are two examples from end-of-class essays:

I feel this class has opened my eyes as an environmentalist to protect and make informed decisions on what tax money is spent where and how tourism positively affects the economy and sometimes negatively affects the sea creatures.

It seems like now anytime I hear someone ... speak about the ocean, I just want to jump in and explain everything I know. ㅁ]

\section{REFERENCES}
American Association for the Advancement of Science (AAAS). 2004. AAAS Survey Report, 9 pp. Available online at: http://www.aaas.org/news/ releases/2004/aaas_survey_report.pdf (accessed October 28, 2008).
Belden Russonello \& Stewart, and American View- point. 1999. Review of Existing Public Opinion Data on Oceans. Conducted for the Ocean Project, 58 pp. Available online at: http://www. theoceanproject.org/images/doc/review.pdf (accessed October 30, 2008)
Centers for Ocean Sciences Education Excellence (COSEE). 2006. Ocean literacy: The essential prin- ciples of ocean sciences, K-12. Available online at: http://www.coexploration.org/oceanliteracy/ documents/OceanLitChart.pdf (accessed October 30, 2008).
Cudaback, C.N. 2006. What do college students know about the ocean? Eos Transactions, American Geophysical Union 87(40), doi:10.1029/2006EO400003.
Garrison, T. 2007. Ocean literacy: An in-depth top ten. Oceanography 20(1):198-199. Available online at: http://www.tos.org/oceanography/issues/issue archive/20_1.html (accessed October 28, 2008).

Cynthia Cudaback (cynthia.cudaback@ gmail.com) is an ocean consultant living in Raleigh, NC, USA. 